ON AN
EXTRAORDINARY CASE OF OVARIAN ASCITES,
TERMINATING FATALLY;
WITN THE APPEARANCES ON DISSECTION.

BY SHIRLEY PALMER, M.D., Tamworth.

A FWw weeks ago $I$ was requested to visit a female, of small stature, aged sixty-two years, who had long been suffering from ascites, and whose abdomen had, at the period of my visit, attained an extraordinary volume. My patient was married, but had never been pregnant. She had, until the commencement of the dropsical affection, enjoyed good health, could assign no cause for it, and complained of few symptoms which might not be satisfactorily traced to the mechanical pressure of the effused fluid upon the abdominal and thoracic organs. The bowels were torpid; the secretion of urine was very scanty; appetite impaired, and thirst moderate. There was no irregularity in the heart's action. The embarrassment of respiration obviously resulted from the diminished capacity of the thoracic cavity. Each of the lower limbs, considerably swollen, exhibited a large patch of superficial ulceration, from which an irritating and offensive ichor constantly exuded. From the enormous distention of the abdominal parietes, it was impossible to form a correct diagnosis of the original seat of the disease; and the imperfect history elicited from my patient served not to throw the faintest light on this important question.

It required, however, little experience or hesitation to decide that, in a case like this, nothing could be effected by internal remedies. The physical energies were rapidly sinking, and it was very evident, that unless means were promptly taken to relieve the internal organs from the increasing pressure, the patient could not long sustain the unequal conflict. Tapping presented itself as the only resource, and as the patient was not in a situation to incur the expense of repeated visits at her own residence, it was proposed that she should be removed to Tamworth, and undergo the operation there, under my own management and inspection.

On Tuesday, Dec. 31 , my patient arrived at Tamworth, excessively fatigued and exhausted by a journey of fourteen miles over the rugged cross-roads of a hilly country. I visited her that evening, found her in a state of great prostration, and decided on deferring the operation until the system had somewhat rallied from the exhausting consequences of the journey.

Day after day, however, my patient grew worse rather than better. Acute and continued pains in the pubic region were added to her other sufferings. Extreme difficulty was now experienced in getting the bowels to act; the secretion of urine did not amount to six ounces in the twenty-four hours. Loathing of food, with nausea, and occasional vomiting of morbid bile, intense thirst, constant restlessness, and increased debility, were experienced. The treatinent consisted principally of mild aperients, stimulating injections, the effervescing draught, with an excess of ammonia, fomentation of the bowels, followed at first by frictions with iodine ointment, and subsequently by an opiate embrocation; and the strength was sustained by the frequent exhibition of animal broths and animal and vegetable jellies.

On the morning of Thursday, Jan. 9 , the attendants were greatly cheered by an evident mitigation of all the worst symptoms, and a rallying of the patient's system from the suffering and depression of the past week.

Saturday morning was now fixed for the performance of the operation, and all the necessary preparations made; but on Friday morning, shortly after midnight, the pain, vomiting, and restlessness recurred in an aggravated form. Food and medicine of every description, and in the minutest quantities, were obstinately rejected; and on Saturday morning, about two o'clock, the distressing conflict terminated in death.

In a few hours after dissolution, my son, Mr. C. Ferrers Palmer, drew from the patient's abdomen more than twelve gallons of pale, limpid, straw-coloured serum. It was cautiously measured, in a graduated vessel, with my own hand, and amounted, as nearly as possible, to ffteen hundred and fiftyeight ounces, or somewhat more than ninety-seven pints. As the specific gravity of the fluid, calculated by an accurate urinometer, was 1010 , the whole weight must have obviously exceeded ninety-eight pounds.

This collection of fluid was contained in an enormous cyst, formed by the right ovary. The parietes of this great sac were about the eighth of an inch in thickness, exceedingly tough, spread over with a network of loaded bloodvessels, and with a multitude of attached, hydatid-like cysts, containing a transparent yellow fluid, and varying in size from the volume of a small apple to that of a garden-pea. Two of the larger cysts were removed for more minute examination; but the majority burst in the effort to detach them. The liver and stomach, perfectly free from any morbid alteration, and the spleen, greatly reduced in volume, were pushed upwards towards the summit of the thoracic cavity. All the other abdominal organs were quite sound.

The patient's body, after the removal of the effused fluid, was calculated, by the husband, to weigh less than seven stone; and consequently not to equal in weight the enormous load of serum which it had previously contained.

Tamworth, April, 1851.

A Anirror

OF THE PRACTICE OF

\section{MEDICINE AND SURGERY IN THE \\ HOSPITALS OF LONDON.}

Nulla est alia pro certo noscendi via, nisi quam plurimas et morborum, et dissectionum historias, tum aliorum proprias, collectas habere et inter s comparare.-Morgagne. De Sed. et Caus. Morb., lib. 14. Proœmium.

\section{ST. THOMAS'S HOSPITAL.}

Lacerated Wound of the Thigh and Leg; Subsequent Ulceration of the Popliteal Artery; Homorrhage; Transfusion; Deligation of the Femoral Artery; A mputation; Second Transfusion. Death. Autopsy.

(Under the care of Mr. SrmoN.)

Ir is not often that an opportunity is afforded to watch the effects of transfusion upon the human subject. Our readers will therefore understand that we felt extremely interested in a case where Mr. Simon resorted to this operation. There are several examples of injection of blood into the veins of females on the point of expiring from hæmorrhage after delivery, the experiments of Dr. Blundell (Medico-Chirurgical Transactions) having contributed in no small degree to create confidence in the minds of surgeons; but transfusion has heen less frequently used to combat the effects of hæmorrhage in male patients, and we thus feel much pleasure in giving publicity to the case lately under the care of Mr. Simon, where every exertion was made on the part of the surgeon and his pupils to counteract the fatal result of extensive loss of blood.

Our readers are aware that transfusion was practised for the first time upon man by Denis and Emmeret, in France, (1666;) in 1667 Lower and King operated in the same manner, and their

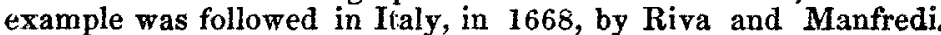
Denis and Emmeret's operation was condemned by the Supreme Court, (Châtelet,) and tranfusion interdicted, until the faculty should approve of the procedure; but this approval was never given, as several fatal cases had occurred. Among these may be mentioned that of a lunatic, who was operated upon three different times, to cure his mental derangement; at the third transfusion he eried out "Stop! I'm choking!" and died instantaneously.

It appears that Drs. Waller and Doubleday thus succeeded, in three cases, in saving lying-in women from imminent death hy hæmorrhage; and several instances have since been recorded, among which is a case of Mr. Green, who, by means of transfusion, revived a man on the point of dying from traumatic hæmorrhage. A mong the physiologists who have declared themselves in favour of transfusion is Majendie. We should, however, observe, that Dieffenbach looked upon the operation as capable of causing instantaneous death. A case of transfusion lately occurred at the Hôpital St. Louis, in Paris, under the care of M. Nélaton; the danger was of a pressing description, and in this instance, as well as in the case we are going to relate, the blood was generously given by a dresser, and the immediate effects were very satisfaetory. The case was one of uterine hæmorrhage; and though the patient died of metro-peritonitis a few days after the operation, it proves that transfusion may, when used under certain circumstances, be of immense benefit.

L'Union Médicale lately mentioned another case, published in the Spanish medical papers, in which a young woman, aged twenty-three, six months advanced in pregnancy, suffered from severe homorrhage, from bursting the vena saphena during a violent effort unconnected with parturition. She became so weak 